\title{
Plant-plant interactions change during succession on nurse logs in a northern temperate rainforest
}

\author{
Carrie Woods ${ }^{1}$, Katy Maleta ${ }^{1}$, and Kimmy Ortmann ${ }^{1}$ \\ ${ }^{1}$ University of Puget Sound
}

March 25, 2021

\begin{abstract}
Plant-plant interactions can vary depending on the severity of the environment. Positive interactions, such as facilitation, are important in early life stages while negative interactions, such as competition, predominate in later stages. Through succession, plant-plant interactions often change from facilitative to competitive. In northern temperate rainforests, gap dynamics result in tree falls that facilitate tree regeneration (nurse logs) as well as bryophyte succession. While the importance of nurse logs for tree seedlings is known, how the interactions of bryophyte communities and tree seedlings vary through succession of the log remains unclear. We examined the relationships of tree seedlings, bryophyte community composition, bryophyte depth, and percent canopy cover in 166 plots on nurse logs and the forest floor in the Hoh rainforest in Washington, USA. Tree seedling density was highest on young logs with early-colonizing bryophyte species (e.g., Rhizomnium glabrescens), and lowest on decayed logs with Hylocomium splendens, a long-lived moss that reaches depths $>20 \mathrm{~cm}$. As a result, bryophyte depth increased with nurse log decay and was negatively associated with tree seedling density. Tree seedling density was $4.6 \mathrm{x}$ higher on nurse logs than on the forest floor, which was likely due to competitive exclusion by H. splendens. Nurse logs had 17 species of bryophytes while the forest floor had six, indicating that nurse logs contribute to maintaining bryophyte diversity. Nurse logs are essential for forest dynamics as they enable both tree seedlings and smaller bryophyte species to avoid competition with the dominant forest floor bryophyte, H. splendens. Given that H. splendens has a global distribution and is often dominant in forested systems across the northern hemisphere, it is likely a widespread driver of plant community structure. Our findings indicate that plant-plant interactions shift with succession on nurse logs from facilitative to competitive and, thus, influence forest community structure and dynamics.
\end{abstract}

TITLE: Plant-plant interactions change during succession on nurse logs in a northern temperate rainforest Carrie L. Woods ${ }^{1}$, Katy Maleta, and Kimmy Ortmann

Biology Department, University of Puget Sound, 1500 N. Warner Ave., Tacoma, WA 98416

Correspondence

Carrie L. Woods, Biology Department, University of Puget Sound, Tacoma, WA, USA. Email: cwoods@pugetsound.edu, ORCID id 0000-0002-2156-3078

\section{ABSTRACT}

1. Plant-plant interactions can vary depending on the severity of the environment. Positive interactions, such as facilitation, are often important in early life stages of plants whereas negative interactions, such as competition, predominate in later stages of growth. Thus, through succession, plant-plant interactions often change from facilitative to competitive. In northern temperate rainforests, gap dynamics result in tree falls that facilitate tree regeneration (nurse logs) as well as bryophyte succession. While the importance of nurse logs for tree seedlings is known, how the interactions of bryophyte communities and tree seedlings vary through succession of the log remains unclear. 
2. We surveyed tree seedlings, bryophyte community composition, bryophyte depth, and percent canopy cover in 166 plots on nurse logs and the forest floor in the Hoh rainforest in Washington. We examined the relationship of bryophyte community composition, bryophyte depth, percent canopy cover, and tree seedling density on nurse logs of three decay classes and the forest floor.

3. Tree seedling density was highest on young logs with early-colonizing bryophyte species, such as Rhizomnium glabrescens, and lowest on decayed logs with Hylocomium splendens a long-lived moss that can reach depths of $>20 \mathrm{~cm}$. As a result, bryophyte depth increased with nurse log decay stage and was negatively associated with tree seedling density. Tree seedling density was 4.6x higher on nurse logs than on the forest floor, which was likely due to competitive exclusion by $H$. splendens. Nurse logs had 17 species of bryophytes while the forest floor had only six, indicating that nurse logs contribute to maintaining bryophyte diversity.

4. Nurse logs are, therefore, essential for forest dynamics as they enable both tree seedlings and smaller bryophyte species to avoid competition with the dominant forest floor bryophyte, H. splendens . Given that $H$. splendens has a global distribution and is often dominant in forested systems across the northern hemisphere, it is likely a widespread driver of plant community structure.

Synthesis: Our findings indicate that plant-plant interactions shift with succession on nurse logs from facilitative to competitive and, thus, influence forest community structure and dynamics.

KEY WORDS: determinants of plant community structure; moss; nurse log; Olympic rainforest; plant-plant interactions; Stress Gradient Hypothesis; structural diversity; temperate rainforest

\section{INTRODUCTION}

Plant-plant interactions are complex and can vary from facilitative to competitive depending on the severity of the external environment (Bertness \& Callaway, 1994; Brooker \& Callaghan, 1998; Callaway \& Walker, 1997). Most positive plant interactions have been found to occur in severe environments (e.g., arid, salt marshes, polar tundra), and happen through the amelioration of those stressful conditions (Brooker \& Callaghan, 1998; Callaway et al., 2002). Facilitation, in particular, appears to be important in colonization and early community development as environments in early succession are typically severe (Callaway \& Walker, 1997; Clements, 1916; Connell \& Slatyer, 1977; Egler, 1954; Gómez-Aparicio, 2009). As the community develops, the amelioration of disturbance and stress by the physical presence of plants (e.g., stabilizing slopes, herbivory protection, microclimate), results in competitive interactions becoming more important over time (Brooker \& Callaghan, 1998; Egler, 1954; Ricklefs, 1977; Walker \& Chapin, 1987; but see Maestre, Valladares, \& Reynolds, 2005). While vascular plants have largely been the focus of plant-plant interaction research, bryophytes can have facilitative or competitive interactions with vascular plants depending on multiple abiotic and biotic factors (Doxford, Ooi, \& Freckleton, 2013; Gornall, Woodin, Jónsdóttir, \& van der Wal, 2011; Gough, 2006; Sedia \& Ehrenfeld, 2003; Soudzilovskaia et al., 2011; Staunch, Redlecki, Wooten, Sleeper, \& Titus, 2012). In locations where bryophytes dominate the ground cover, such as in the arctic and boreal forest, bryophytes can structure the composition of vascular plant communities (Gavini, Suárez, Ezcurra, \& Aizen, 2019; Gornall et al., 2011; Gough, 2006). However, how various stages of bryophyte succession influence vascular plants remains largely unexplored.

In old-growth forests, forest regeneration is often triggered by disturbances, such as tree falls, that create gaps into which early colonizing species proliferate (i.e., small-scale gap dynamics, McCarthy, 2001; Ricklefs, 1977; Yamamoto, 2000). These gaps often result in a change in light levels that facilitate regeneration of early-colonizing shade-intolerant plants if the gaps are large, and shade-tolerant climax species if the gaps are small $\left(<200 \mathrm{~m}^{2}\right)$; colonization of small gaps by the canopy dominants can perpetuate the current canopy species composition (Denslow, Schultz, Vitousek, \& Strain, 1990; McCarthy, 2001; Runkle, 1981). In Appalachian forests in Tennessee, for example, shade-intolerant trees were only able to establish in gaps created by multiple tree falls whereas small gaps were colonized by shade-tolerant trees (Barden, 1981). In contrast, in subalpine fir forests of coastal British Columbia, Pacific silver fir (Abies amabilis ) preferentially colonized all gaps regardless of gap size (Lertzman, 1992). However, western hemlock (Tsuga heterophylla ) was more dominant on stumps in gaps (Lertzman, 1992), suggesting that substrate changes during gap 
formation could also influence forest dynamics. In temperate coniferous forests of the Pacific Northwest, gap regeneration after tree falls can be quite slow ( $>25$ yr, Spies, Franklin, \& Klopsch, 1990), which results in large areas occupied by canopy gaps (13.1\%, Spies et al., 1990). The trees that fall to create these gaps become essential sites of forest regeneration (i.e.nurse logs, Franklin et al., 2002) that cover more area in these forests (up to 25\%) than in other forests $(<4 \%)$ (Harmon et al., 1986). Similar to the subalpine fir forests of British Columbia, these nurse logs provide safe germination sites for late succession tree species', such as shade-tolerant Tsuga heterophylla (Christie \& Armesto, 2003; Harmon \& Franklin, 1989). Nurse logs are thought to facilitate seedlings through several means, such as by becoming a physical barrier between plants and terrestrial fungal pathogens, limiting competition between seedlings, herbaceous species, and bryophytes on the forest floor, and providing nutrients for potential seedling growth (Franklin, Shugart, \& Harmon, 1987; Graham \& Cromack Jr., 1982; Harmon, 1986; Harmon \& Franklin, 1989). They may also be key to maintaining bryophyte diversity.

Nurse logs are sites for bryophyte colonization and succession. In coniferous forests in Colorado, bryophytes were found to colonize logs after lichen establishment (McCullough, 1948), and in coniferous forests of the Pacific Northwest, epiphytic plants from standing trees were replaced by bryophytes more commonly found on the forest floor (Sharpe, 1956). In the Hoh Rainforest in Washington, bryophyte cover on fallen logs reached approximately $90 \%$ in 11-19 y, and succession followed dominance by Dicranum spp. and Hypnum circinale in early succession, Rhizomnium spp. in mid succession, and feather mossesKindbergia oregano and Hylocomium splendens in late succession (Harmon, 1989b). Given that late successional bryophytes are tall and dense enough to prevent tree seedling establishment (Harmon, 1986), they may also out-compete earlyand mid-successional bryophyte species. Thus, nurse logs with moderate decay may be a refuge for earlyand mid-successional terrestrial bryophytes that have difficulty establishing on the forest floor either due to insufficient light or competition with late successional bryophyte species. Thus, gap dynamics may also be important for the maintenance of bryophyte diversity.

These changes in bryophyte communities may have facilitative or competitive interactions with tree seedlings. In the Hoh rainforest, seedling density was highest when logs were dominated by the mid successional bryophytes Rhizomnium spp. and lowest when logs were dominated by late succession bryophytes (Harmon, 1989b). Harmon \& Franklin (1989) argue through their controlled experiments that the interaction of mosses with seedlings changes from facilitative to competitive once the moss layer exceeds $5 \mathrm{~cm}$ in depth. Previous research on bryophyte-vascular plant interactions found that thicker mosses can hinder vascular plants by reducing temperatures and nutrient availability (Gornall et al., 2011; Pearce, Woodin, \& Van Der Wal, 2003). However, they could also hinder vascular plant seedlings by reducing light levels if the bryophytes are thick and dense enough. In coniferous forests, removal of forest floor mosses showed positive effects on tree seedlings (Wardle, Lagerström, \& Nilsson, 2008; Zackrisson, Nilsson, Dahlberg, Jäderlund, \& Jaderlund, 1997). Thus, the importance of nurse logs for tree regeneration may be mitigated by bryophyte communities.

Here we build on the findings of previous studies (Harmon, 1986, 1989b; Harmon \& Franklin, 1989) by diving deeper into the role of bryophyte species on tree seedling density. Over the course of three years, we conducted separate studies in northern temperate rainforests on the Olympic peninsula in Washington State (Hoh rainforest) to examine the importance of nurse logs for tree seedlings focusing on the effects of the nurse log bryophyte community, how that could change with nurse log decay class, and how it may differ from the forest floor. We tested the following predictions: 1) tree seedling density would be higher on nurse logs than on the forest floor, as shown previously (Christie \& Armesto, 2003; Harmon \& Franklin, 1989); 2) bryophyte community composition and the depth of bryophyte mats on nurse logs would influence tree seedling densities (Fukasawa \& Ando, 2018; Harmon \& Franklin, 1989); and 3) the decay class of the nurse log would influence both bryophyte communities and tree seedling densities. Because bryophytes vary in their growth patterns, we also examined if particular bryophyte species were more abundant on the forest floor or nurse logs and were associated with high and low tree seedling density as found previously (Harmon, 1989b). We focused on the dominant feather moss, Hylocomium splendens, given its abundance in these forests and its impact on tree seedling growth in other studies (Fukasawa \& Ando, 2018; Harmon \& Franklin, 1989). We tested our hypothesis that the effect of $H$. splendens on seeding growth was due to competition for light 
by measuring light under and beside this moss. If bryophyte communities on nurse logs change predictably through succession and influence tree seedlings differently at different successional stages, it would further limit the degree of safe regeneration sites in these forests for trees, and highlight the essential role of nurse logs and plant-plant interactions in forest dynamics and diversity maintenance.

\section{MATERIALS AND METHODS}

Study site

Our study was conducted in the Hoh rainforest in the Olympic National Park, a World Heritage Site and Biosphere reserve in Washington State, USA $\left(47^{\circ} 50^{\prime} 08^{\prime \prime} \mathrm{N}, 123^{\circ} 58^{\prime} 54^{\prime \prime} \mathrm{W}\right)$. The climate is mild and extremely wet with an average annual temperature of $10^{\circ} \mathrm{C}$ (range $=-11^{\circ} \mathrm{C}-36^{\circ} \mathrm{C}$ ) and annual rainfall of $3200 \mathrm{~mm}$ (Harmon \& Franklin, 1989). These forests are characterized by large degrees of vertical and horizontal heterogeneity formed by large and tall trees $(>80 \mathrm{~m})$ that are dominated by Picea sitchensis and Tsuga heterophylla, an abundance of large nurse logs (>1 m diameter), a luxurious cover of bryophytes and herbs on the forest floor, and an abundance of epiphytic bryophytes (Franklin et al., 2002; Harmon \& Franklin, 1989).

\section{Survey methods}

We conducted this study over the course of three summers $(2016-2018)$. We counted Tsuga heterophylla and Picea sitchensisseedlings in 166 randomly placed $1 \mathrm{~m} \times 1 \mathrm{~m}$ plots on the forest floor $(\mathrm{n}=52)$ and 1 $\mathrm{m} \times$ nurse log diameter on nurse logs (defined as $>30 \mathrm{~cm}$ diameter and at least $2 \mathrm{~m}$ in length; nurse log diameter ranged from 30 to $104 \mathrm{~cm} ; \mathrm{n}=114)$. For a subset of the nurse log plots $(\mathrm{n}=86)$ and forest floor plots $(\mathrm{n}=12)$, bryophyte composition was surveyed using the point-intercept method. Percent canopy cover was measured as a potential confounding factor using a densiometer placed in the center of each plot. Bryophyte depth was measured $(\mathrm{cm})$ using a caliper in the center of each plot. Because Harmon \& Franklin (1989) found that seedlings that receive less than $0.6 \%$ of light $\left(<12.5 \mu \mathrm{mol} / \mathrm{m}^{2} / \mathrm{sec}\right)$ would not be able to survive, and seedling survival was reduced with high moss biomass (an indicator of moss depth), we also measured light irradiance with a photometer in 50 pairs under and beside thick bryophyte mats focusing on the predominant moss in the forest, Hylocomium splendens. Decay class of each nurse log for each plot was measured using the kick test, which included three levels of decay classes: $1=$ bark still intact upon contact, $2=$ some to various debris falls upon contact, $3=$ foot completely in log, several pieces fragmented off of the log (modified from Christy \& Mack, 1984; Sollins, Cline, Verhoeven, Sachs, \& Spycher, 1987, and Fogel, Ogawa, and Trappe, unpublished report ). These classes correlate with the age of the nurse log so we used them as an indicator of nurse log age (Harmon, 1989b).

\section{Statistical analysis}

To examine if tree seedling density (number of seedlings per $\mathrm{m}^{2}$ ) was higher overall on nurse logs than on the forest floor, we used a Wilcoxon rank test because the data did not meet parametric model assumptions of normality and homogeneity of variance across groups. We used seedling density per area of the plot because area of the plot varied with nurse log diameter. We then examined whether substrate type including forest floor and all three decay classes of nurse logs influenced tree seedling density, bryophyte depth, percent canopy cover, percent cover of the three most abundant bryophyte species (Rhizomnium glabrescens, Hylocomium splendens, Antitrichia curtipendula) using 1-way ANOVA or Kruskal-Wallis tests if parametric model assumptions couldn't be met. Bryophyte depth was missing from one plot and percent cover of $H$. splendens had to be square-root transformed to meet parametric model assumptions.

To determine the factors associated with seedling density, we used a generalized linear model (GLM) with a Poisson error distribution. Explanatory variables included substrate type (nurse log or forest floor), decay class of nurse log, bryophyte depth, \% canopy cover, and bryophyte species with a total percent cover of $>300$ across all plots and that were found in at least 10 plots (Table S1). The bryophyte species included as predictors were: Hylocomium splendens, Rhizomnium glabrescens, Antitrichia curtipendula, Rhytidiadelphus loreus, Sphagnum girgensohnii, and Kindbergia praelonga. We used the dredge function 
in the MuMIn package to determine the model with the lowest Akaike Information Criterion (AIC) value (Barton, 2009). We calculated Spearman rank correlation coefficients for all pairs of explanatory variables using the rcorr function in the Hmisc package in R (Harrell \& with contributions from Charles Dupont and many others, 2020). We included forest floor as decay class 5 in our model. We also calculated variance inflation factors (vif) to test for collinearity among our predictor variables using the vif function in the car package; any vif $<5$ was deemed not correlated.

To examine the influence of substrate (forest floor and nurse logs characterized by decay class) on bryophyte community composition, we conducted a non-metric multi-dimensional scaling ordination (NMDS) using the metaMDS function in the vegan package in $\mathrm{R}$ (Oksanen et al., 2010). We used a Bray-Curtis distance matrix on bryophyte percent cover in each plot. Only plots that had at least two bryophyte species were included $(\mathrm{n}=98)$. We used ellipses to denote variances in bryophyte species composition among substrate types. We fit bryophyte depth (BD), tree seedling density (seedling), and percent canopy cover (CC) as environmental vectors to the NMDS ordination using the envfit function in the vegan package in $\mathrm{R}$ with 1000 permutations (Oksanen et al., 2010). To test for significant differences in species composition among substrate types, we used the adonis function in the vegan package, which is essentially a multivariate analysis of variance. We then used the pairwiseAdonis function in the vegan package to compute all pairwise comparisons among substrate types with adjusted p-values (Martinez Arbizu, 2020).

To test the light levels under and beside Hylocomium splendensmats, we used a paired t-test.

\section{RESULTS}

\section{Substrate type}

In a total of 166 plots, tree seedlings were found in $50 \%$ of our plots. Of those 166 plots, 52 were on the forest floor and 114 were on nurse logs; $36 \%$ of the forest floor plots had tree seedlings whereas $57 \%$ of the nurse log plots had tree seedlings. Tsuga heterophylla was the dominant tree species found as seedlings ( $87 \%$ of all seedlings found). On nurse logs, we found a total of 18 different non-vascular species. Of these 18, there were 16 mosses, one liverwort, and one lichen (Table S2). We found only six different bryophyte species on the forest floor (Table S2).

Tree seedling density was significantly influenced by substrate type, as average tree seedling density on nurse $\operatorname{logs}(20.1 \pm 3.6)$ was $4.6 \mathrm{x}$ greater than on the forest floor $(4.5 \pm 1.8 ; \mathrm{W}=2027.5, P<0.001)$. Substrate type significantly influenced moss depth $\left(F_{3,93}=6.6, P<0.001\right.$, Fig. 1B), and the percent cover of $H$. splendens $\left(F_{3,94}=17.8, P<0.001\right.$, Fig. 1E). No other factor was significantly influenced by substrate type (Fig. 1).

Decay class was significantly positively associated with moss depth and the percent cover of Hylocomium splendens (Table 1). Moss depth was positively correlated with the percent cover of H. splendensand Rhytidiadelphus loreus and negatively correlated with the percent cover of Rhizomnium glabrescens (Table 1). Percent cover of $H$. splendens was negatively correlated with the percent cover of Kindbergia praelonga . Finally, the percent canopy cover was positively correlated with the percent cover of Antitrichia curtipendula (Table 1).

The GLM model that best predicted tree seedling density included substrate type, percent canopy cover as a positive factor, and percent cover of Hylocomium splendens as a negative factor (Table 2). Interestingly, moss depth was a negative factor and percent cover of Rhizomnium glabrescens was a positive factor, so their exclusion from the model may be due to their correlative relationships with the percent cover of $H$. splendens

Bryophyte composition varied significantly with substrate type (adonis, $F_{3,97}=6.8, P=0.001$, Fig. 3). Decay class 1 was significantly different from decay class $3(P=0.006)$ and the forest floor $(P=0.006)$; there were no other significant differences in bryophyte composition among substrate types $(P>0.01$, Fig. 3$)$. These differences were driven by bryophyte species that create thick mats $(>4 \mathrm{~cm})$, such asHylocomium splendens (HylSpl), which were associated with the forest floor and later decay classes of nurse logs (class two and three), 
whereas bryophyte species that don't create thick mats were associated with early decay classes of nurse logs (one), such asRhizomnium glabrescens (RhiGla) and Scapania bolanderi(ScaBol) (Fig. 3). Bryophyte depth was the only factor that had a significant correlation with bryophyte community composition $\left(\mathrm{r}^{2}=0.47\right.$, $p<0.001$ ). While seedling density was higher on nurse logs that were in the early decay class, it did not significantly correlate with bryophyte composition $\left(\mathrm{r}^{2}=0.02, p=0.4\right)$. Canopy cover did not significantly correlate with the NMDS ordination but showed a trend towards decay class $2\left(\mathrm{r}^{2}=0.06, p=0.06\right)$.

Light levels were significantly lower under Hylocomium splendensthan beside it (paired t-test, $t=-10.3$, df $=49, P<0.001$, Fig. S1).

\section{DISCUSSION}

Our study found that tree seedlings were largely affected by bryophyte species identity and the thickness of the bryophyte cover. We found overall that tree seedlings were much more abundant on nurse logs than on the forest floor as found previously (Christy \& Mack, 1984; Harmon \& Franklin, 1989). However, not all nurse logs were created equal; nurse logs at early decay classes supported many tree seedlings and small bryophyte species, such as Rhizomnium glabrescens andScapania bolanderi, while later decay classes had few tree seedlings and bryophyte species with greater depths, such asHylocomium splendens . Moreover, the percent cover of $H$. splendens was negatively associated with tree seedling density and positively associated with bryophyte depth. Our findings are in accordance with Harmon (1989) who found seedling densities highest when nurse logs were dominated by Rhizomnium spp. and lowest when dominated by $H$. splendens . Our findings are also supported by another study conducted in old-growth subalpine spruce forests in Japan where tree seedlings on nurse logs were found to be positively associated with a small liverwort, Scapania bolanderi, and negatively associated with H. splendens (Fukasawa \& Ando, 2018). As in our study, Fukasawa \& Ando (2018) also found that bryophyte community composition shifted from dominance by $S$. bolanderi toH. splendens as nurse logs decayed. Thus, bryophyte succession on nurse logs influenced tree seedlings differently depending on the stage of succession.

As nurse logs decayed, the relationship of bryophyte communities and tree seedlings changed from facilitation to competition. We found support for this in our study as the pattern of seedling density mirrored that of the percent cover of Rhizomnium glabrescens(Figure 1A and 1D) while opposite that of the percent cover ofHylocomium splendens (Figure 1A and 1E), and H. splendenscame out in the model as the only negative driver of seedling density. These patterns are consistent with other studies. In subalpine forests of Japan, Tsuga seedling survival was restricted to nurse logs covered with small bryophyte species (Nakamura, 1992), and in the Hoh Rainforest, seedling establishment was highest on logs with thin mosses as seed retention on bare logs was low, and thick mosses excluded seedlings (Harmon \& Franklin, 1989). While our study and others found correlative support of these relationships, findings from manipulative field experiments provide the strongest evidence. In old-growth forests in western Oregon, for example, seedling emergence was higher on nurse logs of decay class 3 (our class 2) when bryophytes were present than when they were removed (Christy \& Mack, 1984), and in a field experiment in the Hoh Rainforest testing the influence of moss depth on seedling density, seedling density of Tsuga was higher in a moss mat of $3.7 \mathrm{~cm}$ than in $1.4 \mathrm{~cm}$ or $7.8 \mathrm{~cm}$ (Harmon \& Franklin, 1989). The positive effect of bryophytes on tree seedlings could be due to protection from herbivores, increasing moisture or nutrient availability, protecting seeds from being blown off by the wind, or providing a humus substrate into which seedling roots can grow (Graham \& Cromack Jr., 1982; Harmon \& Franklin, 1989; Nakamura, 1992). Many studies have found competitive interactions between bryophytes and tree seedlings (Christy \& Mack, 1984; Fukasawa \& Ando, 2018; Harmon \& Franklin, 1989; Nakamura, 1992). The negative effect of thick bryophytes on tree seedlings could be due to preventing seeds from reaching the humus or soil layer, which can inhibit germination (Iijima \& Shibuya, 2010), the reduction of light levels below the threshold needed for tree seedling germination and survival as found in our study and others (Harmon, 1986; Iijima \& Shibuya, 2010), or reducing nitrogen availability to vascular plants as found in the boreal forest (Gornall et al., 2011). The "window of time" for tree seedling establishment on logs of a particular stage of decomposition seems to be driven by bryophyte succession on logs (Fukasawa \& Ando, 2018), and suggests that the available substrate for successful seedling regeneration is even more 
limited than the area covered by nurse logs would suggest.

The benefits of nurse logs to tree seedlings could be due to a release from competition with forest floor plants. In western Oregon old-growth forests dominated by Pseudotsuga menziesii and Tsuga heterophylla, 98\% of the seedlings in the plot were on nurse logs despite the fact that nurse logs only covered $6 \%$ of the plot, and $T$. heterophylla emergence was higher on mineral soil when litter, bryophytes (such as Hylocomium splendens ) and herbaceous plants were removed than in the forest floor control where nothing was removed (Christy \& Mack, 1984). In the Hoh Rainforest where our study took place, tree seedling survival was significantly higher on the forest floor when bryophytes and vascular plants were removed (Harmon \& Franklin, 1989). Our findings corroborate this, as we found lower seedling densities on the forest floor where $H$. splendens was in high abundance. Our finding that $H$. splendens reduces light levels below the threshold for seedling survival $\left(<12.5 \mu \mathrm{mol} / \mathrm{m}^{2} / \mathrm{sec}\right)$ suggests that the mechanism by which $H$. splendens out-competes tree seedlings is through light competition as suggested previously (Harmon \& Franklin, 1989). Christy \& Mack (1984) also suggest that nurse logs enable seedlings to avoid being covered by litter that dominates the forest floor in western Oregon forests. Interestingly, the small tree seedlings $(<15 \mathrm{~cm})$ that were on the forest floor in our study were on areas covered by litter where bryophytes were not abundant. The tree seedlings we did find on the forest floor or mounds of very decayed nurse logs that were covered in H. splendens were quite tall $(>15$ $\mathrm{cm}$ ), which suggests that seedlings that establish on nurse logs prior to $H$. splendens could grow tall enough to surpass the height of the moss. This could add bryophyte cover as a contributor to the decrease in tree seedling survival after the first 1-2 years of growth (Christy \& Mack, 1984; Friesner \& Potzger, 1944; Haig, Davis, \& Weidman, 1941). While litter may negatively impact tree seedlings, manipulative field experiments with long-term seedling survival data are further required to disentangle the relative influence of bryophytes and litter on tree seedlings both on the forest floor and on nurse logs.

On nurse logs, what drives the initial colonization and subsequent turnover in species composition is largely unknown. Rodents and slugs have been found to disperse lichen and bryophyte propagules (Asplund, Larsson, Vatne, \& Gauslaa, 2010; Barbé et al., 2016; Kimmerer, 1994; Kimmerer \& Young, 1995), and mammals use fallen logs as trails through the forest, so it could be a combination of differences in propagule dispersal ability, germination requirements, and biotic interactions that determine these changes. Alternatively, different decomposer fungi could influence bryophyte community structure on nurse logs as found in alpine forests in Japan (Ando, Fukasawa, \& Oishi, 2017). Thus, the influence of bryophytes on tree seedlings could be mediated by other biotic interactions through a trophic cascade. Regardless, we did find that nurse logs are not only essential for forest regeneration but for the maintenance of bryophyte diversity in late stage forests. We found 17 bryophyte species on nurse logs and only six on the forest floor, and there were significant differences in species composition between our nurse log decay class 1 and the forest floor. Without gap-phase dynamics driven by large tree falls, these early nurse log bryophyte species would eventually be competitively excluded by the late stage bryophytes.

Our results support the predictions of the Stress Gradient Hypothesis that plant-plant interactions are complex and can vary from facilitative to competitive depending on the severity of the external environment (Bertness \& Callaway, 1994). For tree seedlings, some level of bryophyte cover on nurse logs seems to be needed to facilitate germination and seedling establishment, while too much bryophyte cover inhibits germination and seedling survival. Hylocomium splendens, in particular, has been found to consistently exclude seedlings (Fukasawa \& Ando, 2018; Harmon \& Franklin, 1989). This is likely due to H. splenden 's distinctive "stairstep" architecture, which lends it unusual height for a bryophyte. The average lifespan ofHylocomium splendens is 8 years (Binkley \& Graham, 1981), and it dominates nurse logs that are $>30$ years old (Harmon, 1989a). Forest floor bryophytes may have an almost unlimited life span given their continued upward growth (Fenton \& Bergeron, 2006). Thus, unless there is a disturbance that disrupts the dominance by these forest floor bryophytes, the regeneration of the dominant trees will be limited to the small window of opportunity found in early successional stages of bryophytes communities on nurse logs, which is less than 30 years. Interestingly, above the alpine tree line in subarctic tundra in Sweden, spruce tree establishment was improved when planted in bryophyte mats of Hylocomium splendens (Lett, Nilsson, Wardle, \& Dorrepaal, 2017) further supporting that species interactions fall along a spectrum depending on site conditions. Bryophytes, though 
often overlooked in forested ecosystems, could be an important driver of plant community composition and dynamics.

\section{AUTHOR CONTRIBUTIONS}

CLW, KM and KO conceived the ideas and designed methodology; CLW, KM and KO collected the data; CLW and KM analysed the data; CLW led the writing of the manuscript. All authors contributed critically to the drafts and gave final approval for publication.

\section{ACKNOWLEDGEMENTS}

We would like to thank undergraduate students G. Dolkas, E. Didier, J. Wood, and A. Marchand for help with field work. We would also like to thank the Olympic Natural Resources Center in Forks, WA for logistical support. We are grateful to the Olympic National Park for access to the park for research (permits: OLYM2016-SCI-0013; OLYM-2017-SCI-0025; OLYM-2018-SCI-0046) and the Pacific Northwest Permanent Sample Plot Program for access to their plots. Funding was provided by the University of Puget Sound Summer Research Grants for undergraduate students in the Sciences and Math to KM and KO, and the University of Puget Sound Biology department. Authors declare no conflict of interest.

\section{DATA ACCESSIBILITY}

Variables used as predictors of tree seedling density in the GLM, a list of non-vascular species found on all substrate types, and light irradiance under and beside Hylocomium splendens are uploaded as online supporting information. A list of tree seedling density, percent canopy cover, bryophyte depth, and the percent cover of the most abundant bryophyte species in each plot are deposited in the Dryad depository:

\section{LITERATURE CITED}

Ando, Y., Fukasawa, Y., \& Oishi, Y. (2017). Interactive effects of wood decomposer fungal activities and bryophytes on spruce seedling regeneration on coarse woody debris. Ecological Research ,32 (2), 173-182. doi: $10.1007 / \mathrm{s} 11284-016-1427-\mathrm{y}$

Asplund, J., Larsson, P., Vatne, S., \& Gauslaa, Y. (2010). Gastropod grazing shapes the vertical distribution of epiphytic lichens in forest canopies. Journal of Ecology , 98, 218-225.

Barbé, M., Chavel, É. E., Fenton, N. J., Imbeau, L., Mazerolle, M. J., Drapeau, P., \& Bergeron, Y. (2016). Dispersal of bryophytes and ferns is facilitated by small mammals in the boreal forest. Écoscience, 23 (3-4), 67-76. doi: 10.1080/11956860.2016.1235917

Barden, L. S. (1981). Forest development in canopy gaps of a diverse hardwood forest of the southern Appalachian Mountains. Oikos ,37 , 205-209.

Barton, K. (2009). Mu-MIn: Multi-model inference. R Package Version 0.12.2/r18. Retrieved from http://rforge.r-project.org/projects/mumin/

Bertness, M. D., \& Callaway, R. (1994, May 1). Positive interactions in communities. Trends in Ecology and Evolution, Vol. 9, pp. 191-193. Elsevier. doi: 10.1016/0169-5347(94)90088-4

Binkley, D., \& Graham, R. L. (1981). Biomass, production, and nutrient cycling of mosses in an old-growth Douglas fir forest. Ecology ,62 , 1387-1389.

Brooker, R. W., \& Callaghan, T. V. (1998). The Balance between Positive and Negative Plant Interactions and Its Relationship to Environmental Gradients: A Model. Oikos , 81 (1), 196. doi: 10.2307/3546481

Callaway, R. M., Brooker, R. W., Choler, P., Kikvidze, Z., Lortie, C. J., Michalet, R., .. Cook, B. J. (2002). Positive interactions among alpine plants increase with stress. Nature ,417 (6891), 844-848. doi: $10.1038 /$ nature00812

Callaway, R. M., \& Walker, L. R. (1997). Competition and facilitation: A synthetic approach to interactions in plant communities.Ecology , 78 (7), 1958-1965. doi: 10.1890/0012-9658(1997)078[1958:CAFASA]2.0.CO;2 
Christie, D. A., \& Armesto, J. J. (2003). Regeneration microsites and tree species coexistence in temperate rain forests of Chiloé Island, Chile. Journal of Ecology , 91 , 776-784.

Christy, J. E., \& Mack, R. N. (1984). Variation in demography of juvenile Tsuga heterophylla across the substratum mosaic. Journal of Ecology, 72, 75-91.

Clements, F. E. (1916). Plant succession: an analysis of the development of vegetation. Washington: Carnegie Institution of Washington.

Connell, J. H., \& Slatyer, R. O. (1977). Mechanisms of succession in natural communities and their role in community stability and organization. The American Naturalist , 111 (982), 1119-1144. doi: 10.1086/521238

Denslow, J. S., Schultz, J. C., Vitousek, P. M., \& Strain, B. R. (1990). Growth responses of tropical shrubs to treefall gap environments. Ecology , 71 (1), 165-179. doi: 10.2307/1940257

Doxford, S. W., Ooi, M. K. J., \& Freckleton, R. P. (2013). Spatial and temporal variability in positive and negative plant-bryophyte interactions along a latitudinal gradient. Journal of Ecology ,101 (2), 465-474. doi: $10.1111 / 1365-2745.12036$

Egler, F. E. (1954). Vegetation science concepts I. Initial floristic composition, a factor in old-field vegetation development with 2 figs. Vegetatio Acta Geobotanica , 4 (6), 412-417. doi: 10.1007/BF00275587

Fenton, N. J., \& Bergeron, Y. (2006). Facilitative succession in a boreal bryophyte community driven by changes in available moisture and light. Journal of Vegetation Science , 17, 65-76.

Franklin, J. F., Spies, T. A., Pelt, R. V., Carey, A. B., Thornburgh, D. A., Berg, D. R., ... Chen, J. (2002). Disturbances and structural development of natural forest ecosystems with silvicultural implications, using Douglas-fir forests as an example. Forest Ecology and Management. 155: 399-423 . Retrieved from https://www.fs.usda.gov/treesearch/pubs/6026

Franklin, Shugart, H. H., \& Harmon, M. E. (1987). Tree Death as an Ecological Process. BioScience, 37 (8), 550-556. doi: 10.2307/1310665

Friesner, R., \& Potzger, J. (1944). Survival of hemlock seedlings in a relict colony under forest conditions. Butler University Botanical Studies , 6 (1). Retrieved from https://digitalcommons.butler.edu/botanical/vol6/iss1/10

Fukasawa, Y., \& Ando, Y. (2018). Species effects of bryophyte colonies on tree seedling regeneration on coarse woody debris. Ecological Research , 33 , 191-197.

Gavini, S. S., Suárez, G. M., Ezcurra, C., \& Aizen, M. A. (2019). Facilitation of vascular plants by cushion mosses in high-Andean communities. Alpine Botany , 129 (2), 137-148. doi: 10.1007/s00035-019-00222-6

Gómez-Aparicio, L. (2009). The role of plant interactions in the restoration of degraded ecosystems: a metaanalysis across life-forms and ecosystems. Journal of Ecology , 97 , 1202-1214.

Gornall, J. L., Woodin, S. J., Jónsdóttir, I. S., \& van der Wal, R. (2011). Balancing positive and negative plant interactions: How mosses structure vascular plant communities. Oecologia , 166 (3), 769-782. doi: 10.1007/s00442-011-1911-6

Gough, L. (2006). Neighbor effects on germination, survival, and growth in two arctic tundra plant communities. Ecography , 29 (1), 44-56. doi: 10.1111/j.2005.0906-7590.04096.x

Graham, R. L., \& Cromack Jr., K. (1982). Mass, nutrient content, and decay rate of dead boles in rain forests of Olympic National Park. Canadian Journal of Forest Research , 12 , 511-521.

Haig, I. T., Davis, K. P., \& Weidman, R. H. (1941). Natural regeneration in the western white pine type. Tech. Bull. No. 767. Washington, DC: U.S. Department of Agriculture. 99 P., 767 . Retrieved from https://www.fs.usda.gov/treesearch/pubs/48963 
Harmon. (1986). Logs as sites of tree regeneration in Picea sitchensis-Tsuga heterophylla forests of coastal Washington and Oregon. Oregon State University, Corvallis, Oregon, USA.

Harmon. (1989a). Retention of needles and seeds on logs in Picea sitchensis - Tsuga heterophylla forests of coastal Oregon and Washington. Canadian Journal of Botany , 67 , 1833-1837.

Harmon, \& Franklin, J. F. (1989). Tree Seedlings on Logs in Picea-Tsuga Forests of Oregon and Washington. Ecology , 70 (1), 48-59. doi: 10.2307/1938411

Harmon, Franklin, J. F., Swanson, F. J., Sollins, P., Gregory, S. V, Lattin, J. D., . . Cummins, K. W. (1986). Ecology of Coarse Woody Debris in Temperate Ecosystems. In A. Macfadyen \& E. D. Ford (Eds.),Advances in Ecological Research Volume 15 (pp. 133-276).

Harmon, M. E. (1989b). Effects of bark fragmentation on plant succession on conifer logs in the Picea-Tsuga forests of Olympic National Park, Washington. The American Midland Naturalist , 121 , 112-124.

Harrell, F. E., \& with contributions from Charles Dupont and many others. (2020). Hmisc: Harrell Miscellaneous. $R$ package version 4.4-2. Retrieved from https://cran.r-project.org/package=Hmisc

Iijima, H., \& Shibuya, M. (2010). Evaluation of suitable conditions for natural regeneration of Picea jezoensis on fallen logs. Journal of Forest Research , 15 (1), 46-54. doi: 10.1007/s10310-009-0133-9

Kimmerer, R. W. (1994). Ecological consequences of sexual versus asexual reproduction in Dicranum flagellare and Tetraphis pellucida . Bryologist , 97 (1), 20-25. doi: 10.2307/3243344

Kimmerer, R. W., \& Young, C. C. (1995). The role of slugs in dispersal of the asexual propagules of Dicranum flagellare. The Bryologist, 98 , 149-153.

Lertzman, K. P. (1992). Patterns of gap-phase replacement in a subalpine, old-growth forest. Ecology , 73 (2), 657-669. doi: 10.2307/1940772

Lett, S., Nilsson, M.-C., Wardle, D. A., \& Dorrepaal, E. (2017). Bryophyte traits explain climate-warming effects on tree seedling establishment. Journal of Ecology , 105 (2), 496-506. doi: 10.1111/1365-2745.12688

Maestre, F. T., Valladares, F., \& Reynolds, J. F. (2005). Is the change of plant-plant interactions with abiotic stress predictable? A meta-analysis of field results in arid environments. Journal of Ecology , 93 , 748-757. doi: 10.1111/j.1365-2745.2005.01017.x

Martinez Arbizu, P. (2020). pairwiseAdonis. Pairwise multilevel comparison using adonis. $R$ package version 0.4 .

McCarthy, J. (2001). Gap dynamics of forest trees: A review with particular attention to boreal forests. Environmental Reviews ,9 , 1-59.

McCullough, H. A. (1948). Plant succession on fallen logs in a virgin spruce forest. Ecology , 29 , 508-513.

Nakamura, T. (1992). Effect of bryophytes on survival of conifer seedlings in subalpine forests of central Japan. Ecological Research , 7 (2), 155-162. doi: 10.1007/BF02348494

Oksanen, J., Guillaume Blanchert, F., Kindt, R., Legendre, P., O'Hara, B., Simpson, G. L., ... Wagner, H. (2010). vegan: Community ecology package. $R$ Packag, version 1.17-9. http://CRAN.Rproject.org/package=vegan .

Pearce, I. S. K., Woodin, S. J., \& Van Der Wal, R. (2003). Physiological and growth responses of the montane bryophyteRacomitrium lanuginosum to atmospheric nitrogen deposition.New Phytologist , 160 (1), 145-155. doi: $10.1046 / \mathrm{j} .1469-8137.2003 .00875 . x$

Ricklefs, R. E. (1977). Environmental Heterogeneity and Plant Species Diversity: A Hypothesis on JSTOR. The American Naturalist ,111 (978), 376-381. Retrieved from https://www.jstor.org/stable/2460072?seq=4\#metadata_info_tab_contents 
Runkle, J. R. (1981). Gap Regeneration in Some Old-growth Forests of the Eastern United States. Ecology ,62 (4), 1041-1051. doi: 10.2307/1937003

Sedia, E. G., \& Ehrenfeld, J. G. (2003). Lichens and mosses promote alternate stable plant communities in the New Jersey Pinelands.Oikos , 100 (3), 447-458. doi: 10.1034/j.1600-0706.2003.12058.x

Sharpe, G. W. (1956). A taxonomical-ecological study of vegetation by habitats in eight forest types of the Olympic Rain Forest, Olympic National Park, Washington. University of Washington, Seattle.

Sollins, P., Cline, S. P., Verhoeven, T., Sachs, D., \& Spycher, G. (1987). Patterns of log decay in old-growth Douglas-fir forests. Canadian Journal of Forest Research , 17 , 1585-1595.

Soudzilovskaia, N. A., Graae, B. J., Douma, J. C., Grau, O., Milbau, A., Shevtsova, A., .. Cornelissen, J. H. C. (2011). How do bryophytes govern generative recruitment of vascular plants? New Phytologist , 190 (4), 1019-1031. doi: 10.1111/j.1469-8137.2011.03644.x

Spies, T. A., Franklin, J. F., \& Klopsch, M. (1990). Canopy gaps in Douglas-fir forests of the Cascade Mountains. Canadian Journal of Forest Research , 20 (5), 649-658. doi: 10.1139/x90-087

Staunch, A., Redlecki, M., Wooten, J., Sleeper, J., \& Titus, J. (2012). Moss and soil substrates interact with moisture level to influence germination by three wetland tree species. International Scholarly Research Notices Botany , 2012 , 1-6. doi: 10.5402/2012/456051

Walker, L. R., \& Chapin, F. S. (1987). Interactions among Processes Controlling Successional Change. Oikos , 50 (1), 131. doi: 10.2307/3565409

Wardle, D. A., Lagerström, A., \& Nilsson, M.-C. (2008). Context dependent effects of plant species and functional group loss on vegetation invasibility across and island area gradient. Journal of Ecology , 96 , $1174-1186$.

Yamamoto, S.-I. (2000). Invited Review Forest Gap Dynamics and Tree Regeneration. In J. For. Res (Vol. $5)$.

Zackrisson, O., Nilsson, M.-C., Dahlberg, A., Jäderlund, A., \& Jaderlund, A. (1997). Interference Mechanisms in Conifer-Ericaceae-Feathermoss Communities. Oikos , 78 (2), 209. doi: 10.2307/3546287

\section{Hosted file}

image1.emf available at https://authorea.com/users/403904/articles/515215-plant-plantinteractions-change-during-succession-on-nurse-logs-in-a-northern-temperate-rainforest

Figure 1. Average ( \pm SE) tree seedling density of Picea sitchensis and Tsuga heterophylla (A) bryophyte depth (B), percent canopy cover (C), percent cover of Rhizomnium glabrescens(D), percent cover of Hylocomium splendens (E) and percent cover of Antitrichia curtipendula $(\mathrm{F})$ on the forest floor $(\mathrm{n}=12)$ and each decay class of nurse $\operatorname{logs}($ NL $1=$ nurse $\log$ decay class $1, \mathrm{n}=31$; NL $2=$ nurse $\log$ decay class 2 , n $=30$; NL $3=$ nurse $\log$ decay class $3, \mathrm{n}=25)$ in a northern temperate rainforest, Olympic peninsula, WA. Bryophyte depth was missing from one plot. Substrate type significantly influenced bryophyte depth $\left(F_{3,93}=6.6, P<\right.$ 0.001). Substrate type significantly influenced percent cover of $H$. splendens $\left(F_{3,94}=17.8, P<0.001\right)$.

\section{Hosted file}

image2.emf available at https://authorea.com/users/403904/articles/515215-plant-plantinteractions-change-during-succession-on-nurse-logs-in-a-northern-temperate-rainforest

Figure 3. Non-metric multi-dimensional (NMS) ordination of bryophyte community composition on nurse $\operatorname{logs}(\mathrm{n}=98)$ of varying decay stages and the forest floor using a Bray-Curtis distance matrix on percent cover. Two-dimensional stress $=0.16$ with 1000 permutations. The ellipses show the covariance matrix centered on the mean of each nurse log decay stage and the forest floor (solid black line). Nurse logs were classified into three decay stages (modified from Christy \& Mack 1984): NL1 = bark still intact and can hold weight when 
stepped on (light grey dotted line solid black line), NL2 = some to various debris falls upon contact (grey dashed dot line), NL3 = foot completely in log, several pieces fragmented off of the log (dark grey dashed line). Species codes are from Table S1. Environmental variables that significantly correlated with NMS axes are shown in black, heavy arrows and those that did not significantly correlate with axes are shown in grey. Bryophyte depth (BD) correlated significantly with the axes $\left(\mathrm{r}^{2}=0.47, p<0.001\right)$ but not canopy cover $\left(\mathrm{CC}, \mathrm{r}^{2}=0.06, p=0.08\right)$ or tree seedling density (seedling, $\left.\mathrm{r}^{2}=0.02, p=0.4\right)$. Species codes are in red and are the first three letters of the genus and the first three letters of the species (found in Table S2).

Table 1. Spearman rank correlation coefficients between explanatory variables for the generalized linear model for seedling density.

\begin{tabular}{|c|c|c|c|c|c|c|c|}
\hline & Decay class & Bryophyte depth & Hylocomium & Canopy cover & Rhizomnium & Antitrichia & Rhytidiad \\
\hline \multicolumn{8}{|l|}{ Decay class } \\
\hline Bryophyte depth & $0.41 * * *$ & & & & & & \\
\hline Hylocomium & $0.56 * * *$ & $0.58 * * *$ & & & & & \\
\hline Canopy cover & -0.16 & -0.1 & -0.02 & & & & \\
\hline Rhizomnium & -0.18 & $-0.25^{*}$ & -0.17 & -0.13 & & & \\
\hline Antitrichia & -0.13 & 0.05 & -0.17 & $0.32^{* *}$ & -0.19 & & \\
\hline Rhytidiadelphus & 0.05 & $0.4^{* * *}$ & 0.04 & -0.16 & 0.03 & -0.1 & \\
\hline Sphagnum & 0.12 & 0.19 & -0.01 & -0.05 & -0.12 & -0.12 & -0.03 \\
\hline Kindbergia & -0.13 & -0.21 & $-0.24^{*}$ & -0.14 & 0.11 & -0.08 & -0.11 \\
\hline
\end{tabular}

Values in bold indicate a significant correlation between variables. ${ }^{* * *} P<0.001$; ${ }^{* *} P<0.01$; ${ }^{*} P<0.05$

Table 2. Results of the generalized linear model (GLM) analysis showing the predictors of tree seedling density from the best model.

\begin{tabular}{lll}
\hline Factor & Estimate & $\mathrm{SE}$ \\
\hline Canopy cover & $0.019^{* * *}$ & 0.005 \\
Hylocomium cover & $-0.009^{* * *}$ & 0.001 \\
Substrate & $0.315^{*}$ & 0.136 \\
AIC of the best model & 4269.6 & \\
\hline
\end{tabular}

${ }^{*} P<0.05 ;{ }^{* * *} P<0.0001$ 